\title{
BALANCING DUAL ROLES IN SELF-EMPLOYED WOMEN: AN EXPLORATORY STUDY
}

Authors:

Kirsty-Lee McLellan ${ }^{1}$

Koos $\mathrm{Uys}^{1}$

\section{Affiliations: \\ ${ }^{1}$ Department of Human \\ Resource Management, \\ University of \\ Johannesburg, \\ South Africa}

\section{Correspondence to: \\ Koos Uys}

e-mail:

kuys@uj.ac.za

\section{Postal address:}

D Ring 413, Kingsway

Campus, University of

Johannesburg, Auckland

Park, PO Box 524,

Auckland Park, 2006,

South Africa

\section{Keywords:}

self-employed women; mothers; executives; worklife balance; family

\section{Dates:}

Received: 16 Feb. 2008

Accepted: 05 Apr. 2008

Published: 01 May 2009

How to cite this article: McLellan, K., \& Uys, K. (2009). Balancing dual roles in self-employed women: An exploratory study. SA Journal of Industrial Psychology/SA Tydskrif vir Bedryfsielkunde, 35(1), Art. \#416, 10 pages. DOI: $10.4102 /$ sajip.

v35i1.416

This article is available at: http://www.sajip.co.za

C 2009 . The Authors. Licensee: OpenJournals Publishing. This work is licensed under the Creative Commons Attribution License.

\section{ABSTRACT}

This study is aimed at exploring how self-employed women cope in balancing their dual roles as mothers and executives. Through the elicitation of constructs by making use of Kelly's repertory grid technique, the personal construct system of five self-employed white women in Gauteng across varying industries was established. While being successful dual earners, they still bore the primary responsibility for nurturing their families and assuring their well-being. The successful balancing of their dual roles was attributed to the following central themes, which emerged from all the participants: quality time spent with children and family, structure and planning, coping with guilt, support structures and self-reliance, and balance between work and life.

\section{INTRODUCTION}

An unprecedented rise in the employment of married women, fuelled by the feminist movement of the early 1960s, has had far-reaching economic, social and psychological implications for women and their immediate families. With increased opportunities for women in South Africa and given that many women hold high-powered corporate positions or are self-employed, this requires ongoing commitment and availability. Their dual roles as mothers and executives require exceptional coping capacities and skilful balancing to ensure that the needs of all those who depend on them are met and that they are still able to meet their own needs. This indeed requires an artful balancing act of these roles and it could be argued that a potential imbalance in either of these roles could lead to role conflict. It is therefore of interest to know how these women balance their dual roles and to consider the effect that this may have on their well-being.

The domain of 'work and family' emerged as a distinct field of research in the 1960s and 1970s. By the 1980s, what had begun as a narrow research area focusing on working mothers of dual-career families had evolved into an extended domain of study involving researchers from several disciplines and theoretical perspectives.

Menaghan and Parcel helped to define the field in their review of research in the 1980s (Perry-Jenkins, Repetti \& Crouter, 2000). In the 1990s, researchers continued to be intrigued by the interplay between work and family, with particular emphasis on the short and long-term consequences of work for the quality of family life and the development of family members. Phillips and Imhoff (1997) noted that, during the 1990s, considerable emphasis was placed on the differences in stress levels between genders, work-family conflict and coping. Research by Baruch and Barnett (1986), Burke and Greenglass (1989) and Niles and Anderson (1993) related individual, family and work factors to psychological and physical well-being. Indices of psychological well-being included aspects of burn-out, stress and strain, selfesteem and depression. Research by Geller and Hobfoll (1994), Harlan and Jansen (1987), Pines and Guendelman (1995) and Richard and Krieshok (1989) focused on factors considered to have an influence on well-being, which included ethnicity, spouses' views on women's employment, household assistance, occupational levels and the traditional opinion of a woman's occupation.

Perry-Jenkins, Repetti \& Crouter (2000) further highlighted the impact of the 1990s on the work-family interface through technological and economic changes in terms of the increased use of cellular phones, computers and pagers, allowing employees to be more mobile. Furthermore, the 1990s also witnessed an increase in the participation of mothers in the labour force.

From this frame of reference, levels of well-being vary from woman to woman. This may be attributed to their coping mechanisms, personality types or even social, emotional and practical support. Working mothers with a multitude of responsibilities are constantly required to juggle and balance the multiple roles that they face on a daily basis, which may be overwhelming and may adversely affect their wellbeing and health. Weber (1999) stated that the concept of well-being requires an in-depth understanding owing to the implications that this may have on the health of a mother and the overall health and well-being of the family. Ormel, Lindenberg, Steverink and Verbrugge (1999) viewed well-being as a function of overall physical well-being and social well-being. White (1992) saw well-being as perceived life satisfaction and health.

As far as could be established from the available literature reviewed, there are limited data regarding the experiences of self-employed women (in high-level occupations) in South Africa. Most of the literature reviewed focused on women's struggle to enter the workplace, rather than exploring the challenges inherent in coping with high-level work and home life and in finding a balance between the two.

The interest for this study thus falls within the domain of the coping capacity of self-employed mothers. 
More specifically, the aims of the study were:

1. to conduct an exploratory study of how dual executive and mothering roles affected the well-being of self-employed mothers

2. to examine (self-employed) women's self-perceptions and coping mechanisms that facilitate their effective functioning in both the workplace and their home lives.

\section{Research approach}

RESEARCH DESIGN

This study was carried out through use of a qualitative research design. Denzin and Lincoln (2000) highlighted the fact that features of qualitative research operate in a complex historical field that cross-cuts six historical moments operating simultaneously in the present. Hatch (1997) pointed out that the assumptions raised from within these moments have been crystallised into three paradigms of inquiry, viz. the modernist, the interpretive and the postmodernist. This research design falls within the modernist paradigm, as it is aimed at interpreting an individual's reality and the meaning that subjects attribute to everyday lives by means of a formalised qualitative method. Phenomenological theories of personality emphasise the importance of immediate, personal and subjective experience as a determinant of behaviour (Gregory, 1996). The common focus of the various theories, however, has been a person's subjective experience, personal world-view and self-concept as the main thrust of behaviour. Kelly's cognitive approach (1955) to the study of personality emphasised the manner in which individuals perceive and interpret other people and things in their environment and that a person's perception of reality is thus always subject to interpretation. According to Kelly (1955), this could be interpreted as there being no absolute truth and that truth exists in the eye of the beholder. Events may and will exist in the human mind alone and there are various ways to construe them. Kelly's construct theory (1955) focused on the processes that enable people to understand the psychological terrain of their lives (Hjelle \& Ziegler, 1981).

Through Kelly's construct theory, this study describes the meaning of the personal construct formulation of various selfemployed mothers on the balancing of their dual roles and how it affects their well-being.

\section{Participants' profile}

A theoretical sampling, where the aim is not to estimate population parameters but to develop theory that is appropriate to sample groups of people likely to provide theoretical insights, is common to qualitative research (Breakwell, Hammond \& Fife-Schaw, 1997). Esterberg (2002) stated that qualitative researchers usually choose those participants for the specific qualities that they bring to the studies. This is referred to as purposive strategy.

Participants in this study were also intentionally sampled for the specific perspectives that they have. The subject population selected was five white mothers who are self-employed across varying industries within Gauteng. The participants' ages ranged from 36 to 48 . It was also a quintessential requirement of the study that these participants had children. None of the women had more than three children. The children were not required to be of a specific age and the marital and financial status of the participants was not prescriptive. All the participants were married, however, and earned in excess of R15,000 a month

\section{Methods of data gathering}

Participants were interviewed face to face using Kelly's repertory grid technique (Stewart, 2001) as the method of gathering data. This approach was aimed at establishing an individual's construct system from the elements gathered during the participant's interview.
Research interviews require a systematic approach to data collection that allows the researcher to maintain objectivity and achieve valid and reliable results. There is no evidence to suggest that interviews as a data elicitation technique yield data that are less valid or reliable than other methods (Breakwell, Hammond \& Fife-Schaw, 1997). Kelly's repertory grid technique (developed out of his construct theory) uses the concept of the individual possession of personal constructs in an interview situation and that the individual's views of the subject are determined from this (Hjelle \& Ziegler, 1981). This allows the researcher to understand an individual's construct system and the way in which she or he uses it to structure her or his personal environment (Hjelle \& Ziegler, 1981). By making use of Kelly's repertory grid technique, a potential user is able to apply a routine, systematic and standardised method to capture and obtain personal constructs. This infers that Kelly's repertory grid technique has been proved to be reliable and valid as a qualitative research method.

At the beginning of every interview, each participant was asked a set of questions that related to her biographical data. Personal details such as her age, sex, race and job title, the industry within which she worked, and her highest level of education, financial and marital status, and number of children were captured.

Participants were then interviewed by using Kelly's repertory grid technique. The question asked to elicit elements with a positive meaning was, 'Provide three examples of a specific activity that have shown you that you have successfully balanced your roles as mother and executive.' The question asked to elicit elements with a negative meaning was, 'Provide two examples that have shown you that you have not successfully balanced your roles as mother and executive.' Each participant identified a total of five elements.

For the construct elicitation, each participant was required to compare various combinations of three elements (from those identified in the interview process). Participants were then asked to provide one way in which two of the elements were similar and different to the third in terms of the balancing of their dual roles. From these elicited constructs, a matrix of comparisons was produced, which was used to analyse the findings. Constructs elicited were those that showed how and what a mother perceives as being successful or unsuccessful in the balancing of her roles.

\section{Analysis of data}

The analysis of the data followed a qualitative interpretation. Kelly's construct theory looks at the manner in which individuals perceive and interpret people and other factors in their environment (Hjelle \& Ziegler, 1981). This theory focuses on the psychological processes that enable a person to order and understand events in her or his life. The respondent's reality is filtered through different templates or constructs that are needed in order for individuals to understand the world in a consistent fashion.

The analysis of the data thus focused on self-employed mothers' experiences and how their constructs have been established to give meaning to their everyday lives. Although it can be said that constructs vary from person to person, the study aimed at identifying the commonalities that these women experience and what they do to manage their dual roles.

In her book Business applications of the repertory grid, Stewart (2001) outlined five principal methods for manual analysis when Kelly's repertory grid technique is used. These were frequency counts, content analysis, visual focusing, cluster analysis and principal component analysis. The first two methods related to the analysis of the content of the grid and the remaining three methods analysed not only content but also interrelationships. Frequency-count analysis is used when samples of people are interviewed and common trends need to be identified. The same constructs are not reproduced by each participant, 
however, and frequency-count analysis may thus be difficult and limiting. Content analysis provides for the selection of a series of categories into which elements or constructs fall, to which the interviewer is then able to assign the elements or constructs.

The analysis method thus used for this study is a particular form of cognitive mapping uniquely based on the personal construct theory. It was developed following the extensions to the use of repertory grids for the purpose of capturing a 'personal construct system' (Eden, 1993). Through cognitive mapping, the beliefs and values of each participant could therefore be captured to form an individual construct system. This map is made up of constructs linked to form chains around perceptions on the balancing of the dual roles of mother and executive. Cognitive maps place emphasis on the idiosyncratic aspects of a model constructed - it is not meant to be a scientific model of object reality but rather a representation of a part of a world as a particular person sees it, with no right or wrong (Eden, Jones \& Sims, 1983).

The data collected for each participant (captured in an individual repertory grid) were analysed separately. Clusters of similar constructs were grouped together to allow a minimum number of bridging links to other constructs for each participant. Particular constructs from a participant's mental model were selected to depict part of her personal construct system. Main themes were then identified through the isolation of those constructs that were common to all participants.

The interview approach used in this study relied upon participants being able and willing to give accurate and complete answers to questions posed (Breakwell, Hammond \& Fife-Schaw, 1997). The value of Kelly's repertory grid technique compared with a number of other techniques is that the interviewer has a minimalist role and that the participant's views are consequently less susceptible to external contamination. This enhances the credibility and trustworthiness of the study.

Participants are critical collaborators in research and should be treated with respect, dignity and the utmost concern for their welfare (McGuigan, 1997). The topic for this study is ethically acceptable research. All the participants agreed to participate in this study and were free to decline or to withdraw from the research at any time. This was conveyed when all relevant aspects of the study were explained to the participants. Information obtained about the participants is confidential and anonymity was verbalised at the time of the interviews.

\section{FINDINGS}

The individual interviews are discussed below to provide insight into the world of each participant and how she believes she copes with her dual role. Each participant's biographical data are provided up front. With the aid of cognitive mapping, individual themes for all the participants were identified through grouped constructs. These themes provided the basis for each participant's personal construct system. Each theme is explained to detail the participants' personal construct systems. Specific quotes from each interview (given at the end of each theme) are used to support the explanation of the identified themes.

\section{Participant One}

Participant One is a 36-year old white female. She is CEO of a personnel recruitment agency, with five years of experience in the industry. Her highest level of education is a BCompt degree and she is a registered chartered accountant. She is married and has two children aged two and seven. She earns between R30 000 and R45 000 a month.

\section{Identified themes for Participant One}

Individual quality time: She places value on being able to spend individual time with each of her children through planned activities. In this way, she is able to focus on her children, thereby building relationships with them, understanding them better and meeting their needs better. She feels that this interaction is a constructive and emotive achievement. It places less pressure on her and provides her with a sense of satisfaction.

Quoted constructs: 'Better; one-on-one quality time; better balance; specific goal achieved; successful parent; right decision.'

Structure and planning: She has had to develop a structured approach, requiring her to refocus and to prioritise her dual responsibilities. Unplanned activities reduce focus on her children and impact negatively on her work, while planned events reduce any negative impact on both her children and her work. She plans social events to include families with children of the same age, which allows both adult interaction and children's satisfaction. Combining her dual responsibilities does not allow quality time or satisfaction.

Quoted constructs: 'Events must be well planned; controls situations; able to manage the dual role; sacrifice career; family social time balanced.'

Family responsibilities as a priority: Her family is her first priority and she structures her work around her family responsibilities. When she misses routine tasks or when work commitments take priority, she feels less in control and more unsuccessful as a parent. She feels that breaking her children's routine is destructive to them.

Quoted constructs: Feels a failure; irresponsible towards family needs; no balance if work takes preference over family.'

Appeasing guilt: When her work does not allow her to meet her motherly responsibilities, she perceives an imbalance. To compensate, she allows for activities not normally part of her family's daily routine to appease her own sense of guilt. She finds it easier to concede to her children's demands even though she knows that she is spoiling them.

Quoted constructs: 'Against better judgement; less disciplined; irresponsible; conscious negative parenting decision.'

Ability to cope: She believes that she copes because she perceives herself as extremely logical and always tries to control situations. She believes that she has the ability to compartmentalise and can thus manage the dual responsibility. If she makes a mistake, she feels bad but accepts it and moves forward.

Quoted constructs: 'Everything must be well planned; conscious decision to put issues to rest; realistic to the bone; have to do it, so I do it.'

Support structure: She carries out the majority of family responsibilities. Although she has minor child-care assistance, she feels that having a support structure or allowing someone else to manage family responsibilities is not successful to balancing and coping with her dual roles.

Quoted constructs: 'No domestic helper; do as much as possible yourself with your children.'

\section{Participant Two}

Participant Two is a 38-year old white female. She is a selfemployed joint managing director of a public-relations and marketing consultancy, with 15 years of experience in the industry. Her highest level of education is an undergraduate degree. She is married and has three children, one aged 10 months and the other two aged 4 and 9. She earns more than R45 000 a month.

\section{Identified themes for Participant Two}

Time spent individually with children outside the home: Individual activities outside the home provide a greater sense 
of satisfaction and address her children's individual needs more satisfactorily than routine daily activities. These activities have a greater impact on her work, however, since they depend on her availability and are thus harder to maintain. If she misses such an activity or event, she experiences a sense of panic and inadequacy in balancing her dual roles.

Quoted constructs: 'External sense of achievement; not expected by children; sense of delight for children; ad hoc experience, compartmentalised; good mother.

Daily responsibilities: When an activity takes place in the home and includes all her children, there is pressure to maintain her presence but there is also a degree of flexibility. The feeling of guilt if such an activity is missed is less than when an individual activity is missed. She feels hope as a mother when meeting her children's daily needs, as she then has an intrinsic sense of achievement.

Quoted constructs: 'Norm; expected of her as a mother; less stressful if in her own time.'

Organisational ability: Activities are reliant on her as the overall home-maker and on her ability to compartmentalise. This requires a life shift in terms of domestic organisation and time effectiveness in order to fit ongoing home activities into the daily routine.

Quoted constructs: 'Achievable; routine; ongoing commitment; allows for flexibility.

Life balance: An increased separation between work and home responsibilities is required for balance to be achieved. When she is able to balance family and work-life responsibilities, she feels successful and in control as a mother and there is a holistic approach to life.

Quoted constructs: 'Self-satisfaction; "fuzzy" feeling; no guilt, success.'

Guilt: She experiences guilt and a sense of failure when she is not able to meet her children's individual needs through activities outside the home. When work takes priority or she doesn't meet her motherly responsibilities, she feels that she is losing perspective on what is important.

Quoted constructs: 'Children play on the guilt; good cancelled out; enormous guilt; fallen off the wagon.'

Support structure: Even with a support base, she experiences guilt, as her children's immediate needs are being tended to by the domestic worker and not by herself. Despite having a support system, she places pressure on herself to ensure that she is organised and plans well so that she can fulfil her dual responsibilities. Working from home, she battles to differentiate among responsibilities and often feels guilty if she cannot attend to her home life.

Quoted constructs: 'Very hard on myself; more exposed to the dynamics of the home.'

\section{Participant Three}

Participant Three is a 48-year-old white female. She owns a crewing agency as well as a television and film consultancy. She also belongs to a number of professional associations. She has 28 years of experience. Her highest level of education is a postgraduate qualification in education. She is married and has three children aged 9,13 and 16. She earns between R15 000 and R30 000 a month.

\section{Identified themes for Participant Three}

Planned (family) activities: Organised family activities are construed as a normal responsibility of a mother. Proper planning allows her to balance her dual roles of mother and executive. If activities are ad hoc, more time is required to fulfil this responsibility, which impacts on her work time and makes her feel disorganised.

Quoted constructs: 'Structured; alleviates guilt; children have a normal upbringing; content; within her job description; sense of achievement.'

Guilt: Not being there for her children causes her to feel an incredible sense of guilt and resentment because she has missed an important event. Missing an event for her is not being able to provide what is expected of her as a mother and she therefore feels the need to justify her absence.

Quoted constructs: 'Feel horrible within myself; guilt; ashamed; overcompensate; unjust to the children; sense of failure.'

Meeting children's needs: She emphasises the importance of being there for her children and meeting their needs, even if it is during the day, as this puts her in a good mood and gives her a sense of achievement. When this is required of her, however, she often has to work in the evenings and feels irritated when she is not able to do this. This also impacts on her marriage, as it does not allow her to focus on her husband and the family unit.

Quoted constructs: 'Enjoyment in children's sense of happiness; proud; sense of normality; added pressure.'

Work commitments: While she naturally has a responsibility to her work commitments, it is more often than not put aside to meet her family needs. Missed deadlines place more pressure on her to catch up at night. However, being there for her family when needed and having made the time for it have a greater positive impact on her family unit.

Quoted constructs: 'Family demands bit excessive; right to catch up; guilt; not always work flexibility; bad mother.'

Support structure: A purposefully created support system at work allows her to go to greater lengths for her children. This is due to her determination to feel like a mother who is there for her children. Her guilt ensures that she does not 'hand over' her children and make them someone else's problem. She is prepared to sacrifice financially to provide more quality time for her children.

Quoted constructs: 'Determination; income versus more quality time; I must do my part; feel content; husband shares responsibilities.'

\section{Participant Four}

Participant Four is a 40-year-old white female. She is managing director of a professional-services company. She has 23 years of experience in the industry. Her highest level of education is a postgraduate management diploma; she also has a BBA undergraduate degree. She is married and has 3 children aged 5, 13 and 15. She earns an average of more than R45 000 a month. She is the family breadwinner.

\section{Identified themes for Participant Four}

Relationship with children: Although individually focused activities are perceived to be the better decision and are more rewarding, she sees this as potentially selfish towards other members of her family unit. It is also easier for her to be part of a family event, as the consequence or feeling of guilt when she is absent is not as great as when she misses an individually planned event.

Quoted constructs: 'Detrimental to the other children; more effort to focus on individual family members; costs are high; potentially not meeting their expectations.

Building the family unit: Outings with her family, such as a family holiday, imply that there is focus on her family as a unit and that she is meeting her responsibilities as a mother. She feels that this is a more positive and balanced approach to family responsibilities. 
Quoted constructs: 'Positive building experience; feels part of her family unit; involved; fun; time spent is constructive and engaging; conscious decision; relaxed.'

Self-focus: When she makes self-focused decisions, such as socialising with colleagues after work, she experiences this as being destructive to her family unit. Even though she knows that this is the wrong choice in terms of her responsibility, she feels the need to escape.

Quoted constructs: 'Not balanced; irresponsible; consciously not doing the best; no benefit to the family; selfish; sabotage.'

Work commitments as a priority: There is no emotive implication or consequence when she focuses on her work commitments; this is finite and planned. Responsibilities related to family carry more emotion than those related to work and hence require more effort. Because she is the breadwinner, she rationalises meeting her work commitments as her having no choice but acknowledges the negative impact on her family in the longer term.

Quoted constructs: 'No extensive effort; justified; less guilt; no direct reward for her family; torn between family and work; on the periphery; uninvolved; stressful for her family.'

Control and planning: She feels that it is important to plan, as this allows for a balanced approach to meeting her family and work responsibilities. She does not allow others to plan for her, as she likes to be in control. When there is no plan, she feels stressed and is unable to operate properly.

Quoted constructs: 'Conscious decision; more relaxed; under no pressure.'

\section{Participant Five}

Participant Five is a 36-year-old white female. She is legal advisor to public and private partnerships, with 11 years of experience as a lawyer. Her highest level of education is an LLB. She is married and has one child aged two and a half. She is expecting her second child. She earns between R15 000 and R30 000.

\section{Identified themes for Participant Five}

Family responsibilities as a priority: Work commitments are organised around her home responsibilities and only in exceptional circumstances does her work interfere with her responsibility as a mother. This fills her with a sense of pleasure in that she feels that she is managing to 'get it right'. When she is unable to attend to routine responsibilities, it makes her feel that she has not prioritised correctly and that work is interfering with her being a mother. In such a situation, she feels that she could be a better mother.

Quoted constructs: 'Sense of confidence; peace of mind; feel good; positive experience; no guilt; competent, structured.'

Reliance on support structures: She has made a conscious decision to employ support structures that provide her with the means to meet both her work and her family commitments. She relies heavily on the support of her hands-on, self-employed husband.

Quoted constructs: 'Confidence; peace of mind; domestic worker; houseboy; personal assistant; balance.'

Quality time with her child: Individual time spent with her child is perceived as quality time. Being there for her son planned or unplanned - demonstrates a clear understanding of her priorities. Her son always takes priority over work; it is exceptional for work to interfere with this. When unable to spend time with her son, she feels that she is not nurturing enough and could be a better mother and she feels guilty.

Quoted constructs: 'Work structured around son; confirms his importance; responsible; sacrosanct; available; conscious; positive experience; planned.'
Structure and prioritising: She places much emphasis on meeting responsibilities by ensuring structure, planning and time effectiveness. This allows her to cope with her dual responsibility. She spends as little time as possible on unconstructive activities. When ad hoc situations arise that are disorganised, they make her feel that she has not prioritised correctly and she experiences guilt when she is unable to attend to such situations. She further indicated that, to a certain extent, she has had to sacrifice her career to accommodate the arrival of her second child but acknowledged that this was for the betterment of her family unit.

Quoted constructs: 'Routine; regular; structured around son; planned; not disruptive; getting it right; efficiency.'

\section{DISCUSSION}

The aim of this study was to explore how self-employed mothers balanced their dual roles and how this affected their well-being. Through determining these women's self-perceptions and coping mechanisms, an understanding was provided of what they perceived facilitated their effective functioning both at work and at home. Although each of the women's experiences differed regarding the ways in which they balanced their dual roles, distinct similarities or themes emerged from the interviews. These themes included quality time with their children and families, guilt, structure and planning, support structures and self-reliance, and balance between work and life.

The above themes are discussed below, together with supporting literature, to illustrate the source of these women's health and well-being as they endeavoured to cope with their roles both as mothers and as executives.

\section{Quality time with children and family}

Participants in this study all indicated that they felt a need to be organised and that they had to ensure that all their activities and responsibilities were planned to provide for quality time with their families. Time has become the new scarcity and is a fixed commodity. Substantial time commitments to one role, as experienced by the participants, may produce an energy drain that may conflict with the requirements of another role (Edwards \& Rothbard, 1996; Greenhaus \& Beutell, 1985; Polatnick, 2000). Research by Siew Kim and Seow Ling (2001) on the work/family conflict of women entrepreneurs in Singapore suggested that time pressure is measured by the number of hours that are worked and by schedule flexibility. The latter refers to the ability to alter one's work schedule to meet both work and non-work pursuits, including family. They suggested that long hours worked and the usual workschedule inflexibility of self-employed women may lead to high work/family conflict. Research by Hartman and Stoner (1990) also suggested that time pressures bear predominantly on the level and extent of work/family role conflict. Extensive conflict between work and family roles may thus impair an individual's psychological well-being (Greenhaus \& Parasuraman, 2002).

Societal adjustments, such as child-care, fast-food chains and house-cleaning services, alleviate some work/family pressures. Raising children, however, is not so flexible. Moen (1992) highlighted that parents, especially mothers, 'invest' in their children. Moen (1992) as well as Siew Kim and Seow Ling (2001) assumed that the more quality time mothers spend with their children, the better their children's development. If mothers are not able to spend time with their children, they normally experience stress. This was reiterated by the participants in this study. Despite their best intentions, the inevitable outcome of working mothers is a reduction in the amount of time that children spend with their mothers. Moen put forward three dimensions to time spent with children, viz. the number of hours in a day limited to attending to daily activities, the quality of time, and additional time spent with fathers. Moen specifically stated that children may lose hours spent with 
mothers who work but, more importantly, that the loss is in quantity and that this may well be surpassed by the quality of the time that such mothers devote to their children. With regard to the participants in this study, quality time spent with their children, either individually or as a family unit, emerged as one of the predominant themes. All the participants indicated that spending quality time with their children made them feel that they were meeting their children's needs and that they were successful in balancing their roles. White (1995) suggested that work and family need not conflict but that the multiple roles may offer unique psychological benefits. These benefits fulfil different needs for mothers. What appeared important, according to White, was the quality of role involvement rather than role occupancy.

Participants in this study highlighted their preference when events or outings were specifically planned. Ad hoc events placed more pressure on them, as they were not always able to be present and, when they missed these events, their feeling of guilt increased. In their study, Siew Kim and Seow Ling (2001) found that the more hours spent on work increased job/ parent conflict, since time spent with a child enhances the bond between mother and child. Barling (1990) stated that employed mothers have less time for their children, which leads them to compensate by establishing specific time for interaction with their children, as did the participants in this study. There was no strong empirical evidence, however, that showed that the mother/child bond is negatively affected when a mother works full time (Barling, 1990; Pleck, 1979).

The number of children that a self-employed mother has also has a significant correlation to job/parent conflict because of the amount of time and effort required to spend with more children (Siew Kim \& Seow Ling, 2001). Hartman and Stoner (1990) and Moore and Sawhill (1978), among others, supported the notion that larger families increase the work/home role conflict for women but suggested that the size of a family may be significant to self-employed women owing to the autonomy inherent in their work. While this may be a plausible argument, Participants Three and Four, both with three children, felt that most of the quality time spent with their children was as a family unit (versus those participants that had two or one child), as individual time spent was not easy to organise. They did not, however, negate the notion that individual time may have been better for their children.

\section{Guilt}

Throughout all the interviews, the participants in this study constantly referred to feelings of guilt. A lack of focus on their work commitments did not cause them to feel guilty but they did experience guilt when they were not able to meet their children's needs or attend to routine motherly responsibilities.

This guilt could be attributed to high job/parent conflict (Siew Kim \& Seow Ling, 2001). The study by Cannon and Carter (1992) on women entrepreneurs, as that by Conlin (2000), showed that the study subjects felt guilt because were unable to fulfil their traditional maternal role. In most cases, children are a mother's highest priority and working mothers feel guilty for not spending as much time with their children as they believe they should.

This was evident among all the participants in this study, who perceived that, when they were not meeting their children's needs, they were not effectively fulfilling their role as mothers. They experienced this as an imbalance, which led to these feelings of guilt.

Apter (1985) argues that career mothers exhibit the superwoman syndrome. This is fuelled by feelings of guilt. Mothers tend not to accept change in their responsibilities at home and take pride in self-sufficiency. This is unsustainable. They are furthermore keen to nurture and support both husband and children. At the same time, however, they feel that their family should not make allowances for them or be limited by their needs because they have already inconvenienced their family enough by working and by being committed to a career. Many women hope to prove that they are sacrificing nothing and cheating neither work nor home responsibilities. These women give everything because of a need to feel that they are doing their best. Research by Weber (1999) highlighted that, when working mothers were asked what 'well-being' meant to them, most referred to feelings of happiness, winning and absence of guilt.

The participants in this study also expressed absence of guilt as contributing to their happiness. When they managed to meet their commitments as mothers, they experienced happiness, success and achievement in their roles. When they did not achieve the outcome desired, they expressed negative emotion, believing that they had not been able to balance their dual roles.

\section{Structure and planning}

Hoffnung (1992) stated that the value that relates most positively to a woman's satisfaction is the extent of control that she has managed to implement over her lifespan. Hoffnung termed this 'strategic planning'. This entails an individual looking toward the future with the intent of shaping it and doing all things that are possible to achieve her or his vision. This implies perceiving options and making choices. Hoffnung (1992) stated that most career women displayed the quality of strategic planning through preparation for their careers, the planning of a family and the planning of daily and weekly schedules to meet the needs of their work and families. Hartman and Stoner (1990) highlighted the fact that, overall, business owners need to be prepared, be able to structure their time and accommodate many dimensions in coping with the ramifications of the work/ home role conflict.

All participants in this study highlighted the fact that their ability to cope with both work and home life was dependent on their organisational ability. These women had to ensure that there was structure with regard to daily routine as well as the effective planning of activities focused exclusively on their children. Interestingly, some of the women indicated that their career aspirations and focus had shifted to allow for the management of their dual responsibilities with emphasis on the meeting of their children's needs. Most women indicated that they felt disorganised and experienced a lack of balance when there was not a structured and planned approach to their motherly responsibilities. Inversely, when they were organised, they felt a sense of happiness and contentment and that they were 'getting it right' as a mother, hence experiencing less pressure.

With dramatic social transformation in family/work demands, all mothers today have to make decisions on the management of their work and family roles. Drawing on role theory, Kossek, Noe and DeMarr (1999) discussed work/family role syntheses in an article and how individuals managed their work and caregiving roles. This involved decision-making choices governing boundary management and the embracement of multiple roles, with reference to how working mothers managed their joint work and family roles to support productivity both at home and at work. Traditionally, most role theorists have assumed that the social expectations and demands of the management of the care-giving role have often conflicted with those of the work role, work and family roles generally being seen as being in contention with each other. Based on the assumptions of role theory, a work/family role synthesis is therefore defined as the strategy used to manage the dual roles. Boundary management, as one subset of work/family role synthesis, refers to enactment through practical and visible activities involving decisions concerning boundary separation, either high or low, which is 
how an individual is able, mutually and exclusively, to separate the two roles. Role embracement is the time and energy with which one enacts a role (Kossek et al., 1999).

Since boundaries between work and family remain blurred for women who balance dual roles, it can be said that the women interviewed for this study tended to have varying degrees of boundary management in terms of their work and their family. They did, however, repeatedly demonstrate high role embracement as mothers in focusing on constructs such as structure and planning to ensure that they could be there for their children. This provided them with the sense that they were effectively balancing their dual roles.

\section{Support structures and self-reliance}

Apter (1985, p. 10) wrote that

'women cannot accept support from husbands, or others in the way that women usually offer support because they don't believe they deserve it, and they don't know how to accept it. They are used to giving and not receiving support. They encourage people to depend on them. As a result they suffer at times from stress, fatigue and depression, but remain ashamed of their dependency needs and suffer in silence.'

(Apter 1985, p.10)

Support varies according to different dimensions, such as type (emotional), source (friends and family) and level (high or low). Although most studies have not defined support according to these dimensions, research findings have suggested that various sources and types of support moderate role conflict (MacEwen \& Barling, 1988).

The coping effectiveness of working mothers may depend on the nature of the stressor. Aneshensel and Pearlin (1987, p. 77) refer to stressors as 'any set of conditions that threaten the wellbeing of people'.

Barling (1990) suggests two types of coping resources that may act as buffers against the negative effects of stressors: personality hardiness and social support. Personality hardiness comprises three dimensions: commitment to something; events as challenges; and the experience of control over events in one's life. As a personality resource, hardiness is stable and always available in individuals to cope with the sudden impact of a daily acute stressor.

While personality traits or types and the predisposition to cope effectively are certainly not discounted in this study, the data gathered emphasised how social support structures enhanced the ability of the participants to balance their dual roles as selfemployed working mothers.

Social support structures operate differently to personality hardiness and are an external resource available to an individual. Forest and Moen (1990) have stated that professionals can usually afford to purchase services and labour-saving devices to reduce household demands on their time and energy. Parents in higher occupational levels differ from lower to middle-class parents in their ability to withstand the financial costs of combining work and family roles.

Significant to this study was that all the participants were married, were dual income earners and earned in excess of R15,000 a month. This allowed them easier access to paid domestic help or alternative child-care while working during the day. According to Forest and Moen, the accessibility of available resources and the ability to deal with daily strains have a less negative effect on the well-being of parents. While all the participants in this study mentioned their reliance on various support structures, whether these were a spouse, childcare, domestic workers or other forms, most of the women communicated that they were most reliant on themselves as care givers and nurturers. This reaffirmed Apter's statement that women tended not to accept support and relied mostly on themselves. The participants felt that it was a mother's responsibility to care for her children and that they should not be reliant on someone else to take on this nurturing role. Two of the participants had purposefully structured their work support systems to allow them to focus on their children during the day if required.

A report by Ferri and Smith (1996) indicated that the more mothers were involved in work outside the home, the more fathers shared equally in child-care and household work. A considerable degree of gender segregation in parenting roles does, however, remain. Even in those families where both parents were in full-time employment, it was the mothers who took on the major responsibility for domestic life. While reliant on their spouses to some degree, gender segregation was particularly evident when demands were made on the parental time of the participants, as in the care of a sick child or the buying of new shoes for a child. Most of the participants, as opposed to their husbands, took on this responsibility.

\section{Balance between work and life}

All the participants referred to the effective balancing of their dual roles in order to be able to tend to their children's needs and to spend quality time with them or the family unit. For most of the participants, family responsibilities took priority over work. When work had to take preference over family, they felt unsuccessful as mothers and that they were not in control. They felt that their prioritising was not effective.

Greenhaus and Parasuraman (2002) found that the conflict between work and family roles, rather than the time devoted to each role, influenced the amount of stress that individuals experienced in their lives. Individuals experienced stress when they had difficulties in managing the boundaries between different life roles, the participants in this study highlighting the importance of effective ways to manage these boundaries. The participants placed an emphasis on wanting to separate work and family responsibilities and, when they did so successfully, felt that there was a more holistic approach to life. Planning and structure remained at the fore of all the women's ability to balance their dual roles.

Research by Greenhaus and Beutell (1985) suggested that work/ family conflict existed when the time devoted to a requirement, strain from participation and specific behaviours required of one role made it difficult to fulfil the requirements of the other. Work schedules, work orientation, marriage, children and spouse could all produce pressure to participate extensively in work or in family roles. Conflict was also experienced when time pressures were incompatible with the demands of the other role. As a solution, a mother could reduce her working hours, move into a less demanding job or leave the work environment entirely to balance the dual roles.

The participants in this study, however, were self-employed and were not able merely to reduce their hours or move into another job, despite the fact that giving priority to family and children was of the utmost importance to them all.

Moen (1992) divided a woman's commitment to work into four broad categories, viz. the captives, the conflicted, the copers and the committed. Common to 'committed' women, the participants of this study, while they had a strong commitment to marriage and family life, all held high occupational aspirations in that they were self-employed. They did, however, display strong characteristics of 'copers', in that they had successfully managed to work while their children were typically young because they were able to reduce the demands of work to prioritise for family. Most of the women indicated that they were willing to sacrifice their career developments for the sake of their children's needs. 
Participant Four, who was a breadwinner, displayed a stronger tendency toward being "committed' in that she strongly emphasised her work. She did, however, indicate that, when she made self-focused decisions, she deemed this to be selfish and not balanced in terms of her responsibilities as a mother.

The study by Campbell, Campbell and Kennard (1994) further supported the fact that occupational commitment was significantly lower for women with children than for women without children. They found that marriage alone did not impact on a woman's work commitment and that this happened only when children were introduced into the family; the stress of managing multiple roles was greater when work and family responsibilities were both demanding.

Exclusively, employed mothers continued to bear a disproportionate share of household and child-care respo nsibilities. Family obligations moreover increased with parenthood, this increase being greater for women than for men. Men and women often experienced their work and family lives in substantially different ways. Even when working husbands performed a fair share of household tasks, working women still took responsibility for ensuring that the work was done. Employed mothers were therefore expected to experience greater stress and strain than homemakers. Despite full-time employment, dual-earner women still bore the primary responsibility for nurturing and assuring the well-being of family.

Literature on multiple roles has identified two contradictory effects, according to Gill and Davidson (2001). The first effect is the potential stress of combined multiple roles, focusing on the adverse effects of role overload (Gill \& Davidson, 2001; Ivancevich \& Matteson, 1996; Skinner, 1980). The second effect (Barnett \& Baruch, 1987; Parry \& Warr, 1982; Rout, Cooper \& Kerslake, 1997; for example) - that of employment, children and even marriage (Verbrugge, 1993) - is both negative and positive in respect of a mother's psychological well-being. Research by Verbrugge (1983) has suggested that, although working mothers experience more stress, they develop buffers to deal with their dual roles, thus blunting the negative impacts of stress on health. Further research results have showed that positive effects could be found in employed mothers on measures of mental health, self-esteem and mother-role satisfaction (Moen, 1992; Verbrugge, 1983)

\section{Conclusion}

Throughout this research, it was evident to me that a mother's role in the family has not diminished to offset the increase in the average woman's role in the working world. I believe that this means that the balancing of work and family responsibilities remains as large a source of stress for women as previously. The issue for women of coping can moreover not be separated from the interpersonal domain where the values structured into women's experiences are those of care taking, nurturance, empathy and connectedness (Greenglass, 1993).

Until the late 1970s, women remained virtually invisible as managers and entrepreneurs and their absence was generally considered a non-issue. The systematic investigation of women's progress in management and as entrepreneurs remains relatively new. Comparisons of literature reviewed over the last two-and-half decades showed no new evidence to suggest that the perceptions and expectations by outsiders of the role of mother and executive had significantly progressed.

In this study, effective planning and the structuring of responsibilities and events, support systems and quality time spent with children and family indicated that the participants successfully balanced their roles or achieved a balance between work and life. Each participant's personal construct system showed that she continued to rely on herself as nurturer. This gave them all a feeling of being in control and of achievement as mothers. I feel that, while these women were fulfilling dual roles and continued to strive for coping mechanisms to fulfil both roles effectively, the emphasis on the family as a priority remained. It also became clear to me - and this is pertinent that, while they did manage their home lives (albeit not without challenges), they also managed to make significant progress in their careers.

Although not conclusively proved, Strumpfer (1994) suggested that an explanation of the coping mechanisms of married career mothers who experienced a mixture of stress owing to family and work responsibilities could be that they were using each situation as a resource for coping with the other. I believe that it may be important to consider whether the possible increased work satisfaction and achievement of the participants in this study impacted on their sense of achievement as mothers and nurturers and vice versa.

A limitation of this study was that the participants selected to form the sample were white females only. Other ethnic groups and their mechanisms to cope with the balancing of dual roles were not explored. Recommendations for further research are therefore a cross-cultural study to investigate whether the themes identified in this study could serve for all women or whether they are specific to white females. Another limitation of this study was that I did not consider the participants' predisposition in terms of personality type in the balancing of dual roles. Another suggestion for future research is therefore an investigation into the correlation of personality type and ability to cope with dual roles.

A prerequisite of this study was that the participants had children. Another prerequisite was that they could be asked whether the ages of their children could be a determining factor in their well-being. The latter prerequisite, however, was not explored in this study and may therefore be viewed as another limitation. While literature is available on both employed and unemployed mothers and on the impact that this has on their children's development owing to the time that they are able to spend with them, literature on self-employed women is limited. Future research could benefit from looking at how the varying ages of children impact on a self-employed mother's well-being.

From the study undertaken, it may be suggested that the levels of emotional intelligence and continued motherly values of these women may have enabled them to utilise their innate skills in leading, coping and managing both at home and in the workplace. Within a South African context, it can then be said:

We have travelled so far on our journey of transformation that we are another nation, however, we have still so much learning and un-learning to do that our journey has just begun.

(Booysen, 2005)

\section{ACKNOWLEDGEMENTS}

I would like to thank my primary supervisor, Professor Koos Uys, for his constant support and assistance in the completion of this research article. I would also like to thank Professors Lessing and Schurink and the panel committee for their suggestions and support. I also wish to acknowledge my mother, family, friends, partner and Marilyn Shulman for seeing this project through with me. I would not have completed this study without their support and faith in me.

\section{REFERENCES}

Aneshensel, C.S., \& Pearlin, L.I. (1987). Social roles, gender and psychological distress. In R.C. Barnett, L. Biener \& G.K. Baruch (Eds.), Gender and stress. New York: The Free Press.

Apter, T. (1985). Why women don't have two wives. Professional success and motherhood. New York: The Macmillan Press Ltd. 
Barling, J. (1990). Employment, stress and family functioning. Chichester: John Wiley \& Sons Ltd.

Barnett, R.C., \& Baruch, G.K. (1987). Social roles, gender and psychological distress. In R.C. Barnett, L. Biener, \& G.K. Baruch (Eds.), Gender and stress. New York: The Free Press.

Baruch, G.K., \& Barnett, R. (1986). Role quality, multiple role involvement, and psychological well-being in midlife women. Journal of Social Psychology, 51, 578-585.

Booysen, L. (2005). Social identity issues: Challenges facing leadership. Inaugural lecture, Unisa Graduate School of Business Leadership, Pretoria, South Africa.

Breakwell, G.M., Hammond, S., \& Fife-Schaw, C. (1997). Research methods in psychology. (3rd edn.). London: Sage Publications.

Burke, R.J., \& Greenglass, E.R. (1989). Sex differences in psychological burnout in teachers. Psychology Report, 65, 55-63.

Campbell, D.J., Campbell, K.M., \& Kennard, D. (1994). The effects of family responsibilities on the work commitment and job performance of non-professional women. Journal of Occupational and Organisational Psychology, 67, 283-296.

Cannon, T., \& Carter, S. (1992). Women as entrepreneurs. London: Academic Press.

Conlin, M. (2000). The new debate over working moms. Women in business, 52(8), 18-23.

Denzin, N.K., \& Lincoln, Y.S. (2000). Handbook of qualitative research. (2nd edn.). Thousand Oaks: Sage Publications.

Eden, C. (1993). Strategy development and implementation: Cognitive mapping for group support. In J. Hendry \& G. Johnson with J. Newton (Eds.), Strategic thinking: Leadership and the management change. Chichester: John Wiley \& Sons Ltd.

Eden, C., Jones, S., \& Sims, D. (1983). Messing about in problems: An informal structured approach to their identification and management. East Lansing: Pergamon Press.

Edwards, J., \& Rothbard, N. (April, 1996). An empirical examination of the person-environment fit within and between work and family domains. Paper presented at the 11th Annual SIOP Conference, San Diego, CA.

Esterberg, K.G. (2002). Qualitative methods in social research. New York: McGraw-Hill.

Ferri, E., \& Smith, K. (1996). Parenting in the 1990s. Social policy research (106), 1-6. Retrieved October 10, 2005, from http:// www.jrf.or.uuk/knowledge/findings/socialpolicy/sp106. asp

Forest, K.B., \& Moen, P. (1990). Working parents, workplace supports, and well-being: The Swedish experience. Social Psychology Quarterly, 53(2), 117-131.

Geller, P.A., \& Hobfoll, S.E. (1994). Gender differences in job stress, tedium and social support in the workplace. Journal of Social Psychology, 11, 555-572.

Gill, S., \& Davidson, M.J. (2001). Problems and pressures facing lone mothers in management and professional occupations - a pilot study. Women in Management Review, 16(8), 383-399.

Greenglass, E.R. (1993). Social support and coping of employed women. In B.C. Long \& S.E. Kahn (Eds.), Women, work and coping. Montreal: McGill-Queen's University Press.

Greenhaus, J.H., \& Beutell, N.J. (1985). Sources of conflict between work and family roles. The Academy of Management Review, 10(1), 76-88.

Greenhaus, J.H., \& Parasuraman, S. (2002). The allocation of time to work and family roles. In D.L. Nelson \& R.J. Burke (Eds.), Gender, work stress and health. Washington, DC: American Psychological Association.

Gregory, R.J. (1996). Psychological testing: History, principles and applications. (2nd edn.). Needham Heights: Allyn and Bacon.

Harlan, H.L., \& Jansen, M.A. (1987). The psychological and physical well-being of women in sex-stereotyped occupations. Journal of Employment Counselling, 24, 31-39.

Hartman, R.I., \& Stoner, C.R. (1990). Work-home role conflict in female owners of small businesses: An exploratory study. Journal of Small Business Management, 28(1), 30-39.
Hatch, M. (1997). Organizational modern symbolic, and postmodern perspectives. Oxford: Oxford University Press.

Hjelle, L.A., \& Ziegler, D.J. (1981). Personality theories: Basic assumptions, research, and applications. (2nd edn.). New York: McGraw-Hill.

Hoffnung, M. (1992). What's a mother to do? Conversations on work $\mathcal{E}$ family. Pasadena: Trilogy Books.

Kelly, G. (1955). A cognitive theory of personality - Personal construct theory. In L.A. Hjelle \& D.J. Ziegler (1981). Personality theories: Basic assumptions, research, and applications. (2nd edn.). New York. McGraw-Hill.

Kossek, E.E., Noe, R., \& DeMarr, B. (1999). Work-family role synthesis: Individual and organisational determinants. International Journal of Conflict Management, 10(2), 102-130.

MacEwen, K.E., \& Barling, J. (1988). Interrole conflict, family support and marital adjustment of employed mothers: A short-term, longitudinal study. Journal of Organisational Behaviour, 9(3), 241-250.

McGuigan, F.J. (1997). Experimental psychology: Methods of research. (7th edn.). Upper Saddle River: Prentice Hall.

Moen, P. (1992). Women's two roles. A contemporary dilemma. New York: Auburn House.

Moore, K.A., \& Sawhill, I.V. (1978). Implications of women's employment for home and family life. In P. Voydanoff (Ed.) , Work $\mathcal{E}$ family. Palo Alto: Mayfield Publishing Company.

Niles, S.G., \& Anderson, W.P. (1993). Career development and adjustment: The relation between concerns and stress. Journal of Employment Counselling, 30, 79-87.

Ormel, J., Lindenberg, S., Steverink, N., \& Verbrugge, L.M. (1999). Subjective well-being and social production functions. Social Indicators Research, 46(1), 61-91.

Parry, G., \& Warr, P. (1982). Paid employment and women's psychological well-being. Psychological Bulletin, 8(1), 498519.

Perry-Jenkins, M., Repetti, R.L., \& Crouter, A.C. (2000). Work and family in the 1990s. Journal of Marriage E Family, 62(4), 981-999.

Phillips, S.D., \& Imhoff, A.R. (1997). Women and career development: A decade of research. Annual Review of Psychology, 48, 31-59.

Pines, A., \& Guendelman, S. (1995). Exploring the relevance of burnout to Mexican blue collar women. Journal of Vocational Behaviour, 47, 1-20.

Pleck, J.H. (1979). Men's family work: Three perspectives and some new data. In P. Voydanoff (Ed.), Work \& Family. Palo Alto: Mayfield Publishing Company.

Polatnick, M.R. (2000). Working parents. National Forum, 80(3), 38-42.

Richard, G.V., \& Krieshok, T.S. (1989). Occupational stress, strain, and coping in University faculty. Journal of Vocational Behaviour, 34, 117-132.

Rout, U.R., Cooper, C.L., \& Kerlaske, H. (1997). Working and non-working mother: A comparative study. Women in Management Review, 12(7), 264-275.

Siew Kim, J.L., \& Seow Kim, C. (2001). Work-family conflict of women entrepreneurs in Singapore. Women in Management Review, 16(5), 204-221.

Skinner, D.A. (1980). Dual-career family stress and coping. In P. Voydanoff (Ed.), Work \& family. Palo Alto: Mayfield Publishing Company.

Stewart, V. (2001). Business applications of the repertory grid. Chapters 1-7. Retrieved August 15, 2005, from http://www. enquirewithin.co.za/bus_app

Strumpfer, D.J.W. (1995). The origins of health and strength: From "salutogenesis" to "fortegenesis". South African Journal of Psychology, 25(2), 81-89.

Verbrugge, L.M. (1983, August). Pressures, satisfactions and the link to physical health of young women. Paper presented at a meeting of the American Psychological Association. Anaheim, CA.

Verbrugge, L.M. (1993). Marriage matters: Young women's health. In B.C. Long \& S.E. Kahn (Eds.), Women, work and coping. Montreal: McGill-Queen's University Press. 
Weber, G.J. (1999). The experiential meaning of well-being for employed mothers. Western Journal of Nursing Research, 21(6), 785-796.

White, B. (1995). The career development of successful women. Women in Management Review, 10(3), 4-15.
White, J.M. (1992). Marital status and well-being in Canada. Journal of Family Issues, 13(3), 390-401. 